\section{The Publics of public health}

\section{William Coleman}

\section{Endangered Lives: Public Health \\ in Victorian Britain.}

By Anthony S. Wohl.

J.M. Dent: 1983. Pp.440. £17.50.

OVER the past forty years public health in Victorian Britain has remained a subject of uncommon historical interest and has generated a large body of valuable scholarship. The scope of the subject is immense, involving virtually the full range of biological, environmental, economic, political and social conditions that can influence human well-being and the documentary material, available for assaying the character of these conditions, is almost overwhelmingly abundant and diverse. Is there a way through this labyrinth? How can one begin to appreciate the multiple and interrelated meanings of the critical word "public"? (The meaning of "health" is itself another and vast problem, not addressed directly in this book.)

With singular boldness Anthony S. Wohl has attempted to create an integrated and critical portrait of the public health affairs of the age. He draws upon and makes imaginative use of available scholarly material (his references provide an excellent guide to relevant publications) and works also with the inexhaustible resources of Parliamentary Reports, other govern- ment publications and contemporary general and medical literature. This is not the first such synthetic account (F.E. Smith's The People's Health should be mentioned) but Wohl's work stands out for its comprehensiveness and clarity of presentation. The latter is much assisted by the author's mastery of his material and his willingness to explore the diverse and not always immediately obvious aspects of a problem (see, for example, his discussion of infant mortality in relation to class standing, the plight of the working mother, breast versus bottle feeding, the obscure causes of infant diarrhoea and the persistence of the problem into the twentieth century).

The organization of Endangered Lives is simple and effective. After describing the condition of child and adult in the industrial city (Wohl does not neglect, importantly, the much less familiar misery of rural life), he discusses sewerage, fevers, overcrowded housing and man's fine capacity for fouling his nest, thereby either shortening his life or rendering it altogether nasty. Public action and inaction, too, are examined, with stress upon conflicts between local and central governments and the agonizing process of legislative innovation and even slower implementation of remedial measures.

There are many "publics" in this story: officialdom at various levels and representing rival interests; the producers and consumers of society's offal, the latter being especially the true subject of the word "public"; the working class; the medical profession, whose interest occasionally favoured closer scrutiny and concern for the labouring poor but often did not. Public health was, and is, therefore, a matter for neither legislator nor physician alone but one that reaches over the population and most crucially affects society's economically and politically most impotent members. Wohl stresses this point (but also notes the absence of working class agitation regarding specific public health matters); it is, in fact, the life of the poor or marginally secure that is the central subject of his book. This is an outstanding work of thoughtful synthesis and a paperback edition in the near future, would be very welcome.

William Coleman is Professor of History of Science and History of Medicine at the University of Wisconsin, Madison.

\section{Entropy, evolution and Cheshire cats}

\author{
John Lawton
}

\section{Adaptability: The Significance of}

Variability from Molecule to

Ecosystem.

By Michael Conrad.

Plenum: 1983. Pp.383. \$42.50, £29.75.

Most biologists are interested in the adaptations of organisms; very few will find those interests reflected in Conrad's book. Indeed, my guess is that most of them will find it extremely difficult, if not impossible, to understand. I have several reasons for coming to so critical a conclusion.

The book attempts to review patterns of adaptive change in living things, ranging from molecules to whole ecosystems. However, the basic concepts are formally developed using thermodynamics and information theory. The result is often a dense, impenetrable string of equations with components defined many pages earlier, but with no appendix to remind the struggling reader what each variable means. If hard ideas are unavoidable, notation is not something that readers should have to wrestle with.

Second, Conrad's style when dealing with difficult ideas does not help. I had the curious experience of reading sentences in which individual words were perfectly understood, but where the whole conveyed no meaning. Consider the following: "For adaptability the main relevant point is that biological systems are capable of coping with disturbances if they are capable of forgetting these disturbances. In general forgetting disturbance means that disturbance is ultimately dissipated into a heat bath". Quite so, but what does it mean? Or "The idea of a partial state is a little like the smile of the Cheshire cat, except that we are eventually interested in finding the cat". I wonder if Conrad really intended to draw so close an analogy with Alice's bizarre imaginary world? Of course, it is perhaps unfair to take bits of text out of context but in context, I often found his ideas no easier to comprehend.

If my main problem with the book was unfamiliarity with its basic ideas, it was compounded by a failure on the part of the author to convince the hapless reader that it would all be worth it in the end. It is not at all obvious, for example, why "statistical characteristics of the ecosystem are fundamental from the standpoint of adaptability"'. Yet two early chapters plunge straight into descriptions of these statistical characteristics in terms of entropy measures of transition probabilities of ecosystem states. To the working biologist, the sheer impossibility of ever measuring transition probabilities between ecosystem states defined over the whole hierarchy of levels from populations 